\title{
Is adaptation of orientation-specific cortical cells a plausible explanation of illusion decrement?
}

\author{
STANLEY COREN \\ University of British Columbia, Vancouver, British Columbia, Canada \\ JOAN S. GIRGUS \\ Princeton University, Princeton, New Jersey \\ and \\ DIANE SCHIANO \\ Oberlin College, Oberlin, Ohio
}

\begin{abstract}
A modified Müller-Lyer illusion was used to test whether the adaptation of orientation-specific cells contribute to illusion decrement. Subjects either scanned the illusion configuration (a condition known to produce decrement), fixated one vertex of the illusion configuration, scanned a field of parallel lines set at the same angle from the horizontal as the wings of the illusion configuration (to adapt the orientation-specific receptors), or scanned a field of randomly spaced dots. Over the 5-min test period, those subjects who scanned the illusion configuration between judgments showed significantly more illusion decrement than did any of the other three groups. This suggests that active exploration of the illusion figure, rather than adaptation or fatigue of orientation-specific contour detectors in the cortex, is required for illusion decrement to occur.
\end{abstract}

It is well known that the magnitude of many visual geometric illusions decreases during periods of free inspection (Coren \& Girgus, 1972a, 1972b, 1978a; Girgus \& Coren, 1982; Parker \& Newbigging, 1963; Porac \& Coren, 1977). This reduction of illusion strength has been called illusion decrement. The causes of illusion decrement, however, still remain to be determined and have been the subject of some debate.

The most frequently encountered explanation is that illusion decrement involves some form of perceptual learning that occurs during the active exploration of the illusion stimulus and, thus, results from the normal information processing of the stimulus (Coren \& Girgus, 1974, 1978a, 1978b). For example, when viewing the Müller-Lyer figure, subjects tend to emit overly long eye movement when inspecting the apparently longer segment, and to emit too short eye movements for the apparently shorter segment. These erroneous eye movements may then provide information as to the existence, size, and direction of the illusion. Such error feedback may provide the basis for the recalibration of the illusory percept.

This research was supported in part by a grant from the Natural Sciences and Engineering Research Council of Canada and in part by Grant 74-18599 from the National Science Foundation. It represents the equal and shared contributions of the authors. The authors would like to thank Carole Schaffer for her assistance in stimulus generation.

Requests for reprints should be sent to: S. Coren, Department of Psychology, University of British Columbia, Vancouver, British Columbia, Canada V6T 1W5.
This position is supported by the fact that illusion decrement is greatest when free eye movements are permitted and least under conditions of steady fixation (Coren \& Girgus, 1978a; Coren \& Hoenig, 1972; Day, 1962; Festinger, White, \& Allyn, 1968).

In contrast to the more cognitive orientation mentioned above, some researchers suggest that illusion decrement may arise through some structural mechanism. These theories usually begin with the presumption that the illusion itself is caused by some form of interaction between orientation-specific receptors in the cortex (e.g., Burns \& Pritchard, 1971). Given such a theoretical position as a starting point, one need only suggest that these orientation-specific cells in the cortex, which are initially responsible for the formation of the illusion, begin to fatigue or adapt as the result of continuous inspection of the illusion figure. Actually, such explanations of illusion decrement may be grouped into two classes. The first proposes fairly specific processes which oppose the continuation of the illusion-forming mechanism, whereas the second class proposes more global explanations.

The more specific theories can be seen as updated versions of the original cortical satiation theory (Koehler \& Fishback, 1950a, 1950b; Koehler \& Wallach, 1944). The nature of this updating involves the substitution of more modern physiological models of the operation of the visual cortex (rather than the original field conception) to provide a mechanism for altering the inclination of lines and, hence, the angles making up the illusion. In effect, one 
is altering the "cortical image" of the stimulus in order to produce a reduction in the magnitude of the observed distortion. These are the same theories which have been used to explain the tilt normalization effect (Gibson \& Radner, 1937), which occurs with continuous viewing of an oblique line. With continuous inspection, the orientation of an oblique line undergoes an apparent shift toward the horizontal or vertical meridian (whichever is closer). It has been postulated that this shift in apparent orientation occurs as a result of two factors: the fatigue or adaptation of the cortical cells tuned to the same orientation as the viewed line (Coltheart, 1971; Howard, 1982) combined with a preponderance of orientation-specific cells in the cortex which are tuned to the horizontal and vertical meridians (Mansfield, 1974; Mitchell, 1980). As an example, suppose that the maximal magnitude of the Müller-Lyer illusion occurs for wings angled about $45^{\circ}$ from the horizontal, as suggested by some researchers (Auerbach, 1894; Coren, 1981; Nakagawa, 1958; Restle $\&$ Decker, 1977); then any shift in the apparent orientation of the lines that make up the wings of the illusion toward the horizontal or vertical meridians will produce a less optimal illusion-inducing angle, and hence lowered illusion strength.

A more general structural explanation for illusion decrement, which makes fewer assumptions but equally well predicts illusion reduction with prolonged viewing, depends on the notion that the original illusory effect is caused by some form of interaction between orientationally tuned cortical receptors, as has been suggested by several researchers (e.g., Blakemore, Carpenter, \& Georgeson, 1970; Burns \& Pritchard, 1971). With continued inspection of contours oriented to elicit the maximal response of a particular population of such cells, the cells will selectively fatigue (Graham \& Nachmias, 1971; Harris, 1981; Howard, 1982). This approach argues that, if with continued inspection of the figure, the population of cells responsible for the interactions which cause the illusion becomes less responsive due to the operation of this fatigue, then the illusory distortion will begin to attenuate, resulting in the usually observed illusion decrement.

The structural mechanisms that have been suggested to explain illusion decrement are difficult to evaluate on purely theoretical grounds. Since no studies to date have directly established whether adaptation or fatigue of orientation-specific cells can cause a reduction in illusion magnitude, which mimics that observed in illusion decrement studies, the following experiment was conducted to provide these data.

\section{Method}

\footnotetext{
Subjects

Eighty university student volunteers served as subjects. Each had normal or corrected-to-normal vision, and each was naive as to the purpose of the experiment. Twenty subjects were randomly assigned to each of four conditions.
}

\section{Stimuli and Apparatus}

The standard form of the Müller-Lyer configuration is fairly complex, containing five different contour orientations. In order to simplify theoretical interpretation of the results, we used a minimal version of the overestimated segment of the illusion, which contains only one contour orientation. This figure, shown as Figure 1, was originally introduced by Sanford (1898) and has been used in other studies in which a minimal configuration has been needed (e.g., Coren, Girgus, Ehrlichman, \& Hakstian, 1976; Restle \& Decker, 1977), and has been shown to produce illusion decrement with active viewing which is similar in rate and magnitude to other variants of the Müller-Lyer figure (Coren \& Girgus, 1978a).

The illusion stimuli were photographed on motion picture film and appeared as white figures on a black background. The lines in the illusion configuration were $3 \mathrm{~mm}$ wide. The test horizontal was $8 \mathrm{~cm}$ in length ( $8^{\circ}$ visual angle); the wings of the illusion were $2 \mathrm{~cm}$ long and made an angle of $45^{\circ}$ with the horizontal. The stimulus films were projected onto a screen that was placed $56 \mathrm{~cm}$ from the subject. There was a black fixation point, $1 \mathrm{~mm}$ in diameter, in the center of the screen at all times. When the illusion configuration was projected on the screen, it was oriented so that the fixation point fell at the right end of the horizontal extent to be judged, as indicated in the figure.

Three inspection stimuli were used, depending upon the condition. Each appeared as part of a separate stimulus-judgment film sequence. For the two standard decrement conditions (differing only in the availability of free eye movements) the illusion configuration was used as both the test and inspection stimuli. In the condition designed to maxially adapt the relevant orientation-specific neurons, the inspection stimulus was a grid of lines, $3 \mathrm{~mm}$ in width with 4-mm separations, inclined at $45^{\circ}$, thus matching the width and the inclination of the wings of the illusion. A control inspection field consisted of dots, $2 \mathrm{~mm}$ in diameter, spaced at random intervals that varied from 2 to $6 \mathrm{~mm}$.

On each film there were six illusion-judgment sequences with five 1-min inspection periods between them.

\section{Procedure}

After their heads were immobilized in a chin and forehead rest, subjects viewed the arrays. In each of the four conditions, subjects were asked to make six judgments of the length of the illusion figure. After the initial measurement, each subsequent measurement of illusion magnitude was preceded by $1 \mathrm{~min}$ of viewing the relevant inspection pattern. During each measurement, the subject fixated the black dot on the right extreme of the horizontal extent to be judged. At the beginning of each measurement sequence, a 5-mm-wide white dot appeared $14 \mathrm{~cm}$ to the right of the illusion configuration. The white dot then moved toward the illusion configuration in 2-mm steps. The subject's task was to judge when the distance between the white dot and the upper end of the right-hand wing of the illusion configuration (which was in the center of the screen under the fixation point) was equal to the length of the horizontal test extent.

The four conditions differed only in what the subjects were asked to view during the inspection periods between judgments, or in how they were to view it. There were two conditions in which the illusion figure was present during the inspection periods. In the standard decrement condition, subjects were required to scan back and forth across the horizontal test extent defined by the wings of the illusion configuration

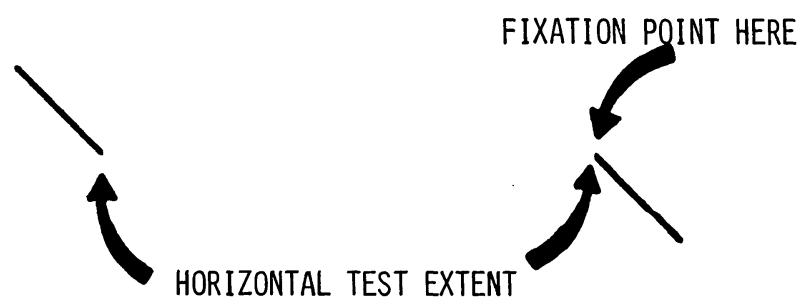

Figure 1. The minimal version of the overestimated segment of the Müller-Lyer illusion used as a stimulus. 
for 1-min intervals between each measurement sequence. Previous research has shown that these are the optimal conditions for illusion decrement to occur (see Coren \& Girgus, 1978a for a review). The second group continued to fixate the fixation point located at the rightmost extreme of the test extent during the inspection periods. In the adaptation condition, subjects scanned the grid of slanted lines throughout each inspection period, whereas in the control condition, subjects were asked to scan the field of randomly spaced dots.

\section{RESULTS AND DISCUSSION}

The data from the four conditions are presented in Figure 2, which plots illusion magnitude against inspection time. The most direct analysis that can be made of these data is simply to assess the amount of illusion decrement that has been obtained under each inspection condition by subtracting the final illusion magnitude (after 5 min of inspection) from the initial illusion magnitude (prior to any inspection). A one-way analysis of variance indicated a significant difference among the groups $[F(3,79)=3.50, p<.025]$. The pairwise differences among the means, which are the theoretically most relevant comparisons, were tested using Tukey's HSD procedure. The mean decrement for the condition in which subjects actively scanned the illusion figure $(9.1 \mathrm{~mm})$ was significantly greater than the mean decrement for the other three groups $(p<.05)$. Conversely, the mean reduction in illusion for the group that scanned the field of $45^{\circ}$ slanted lines (and presumably, experienced maximal adaptation of the orientation-specific cells tuned for the same degree of inclination as the wings of the illusion figure) was only $2.3 \mathrm{~mm}$. This latter value was not statistically different from the amount of decrement observed for the group that scanned the field of random dots $(3.6 \mathrm{~mm})$ or for the group that steadily fixated the illusion figure $(2.5 \mathrm{~mm})$.

An alternate way of looking at these data is to consider the actual amount of illusion decrement observed for each group separately. An analysis of variance of the change in illusion magnitude as a function of inspection time was conducted for each group independently. This analysis indicated that there was significant reduction of illusion

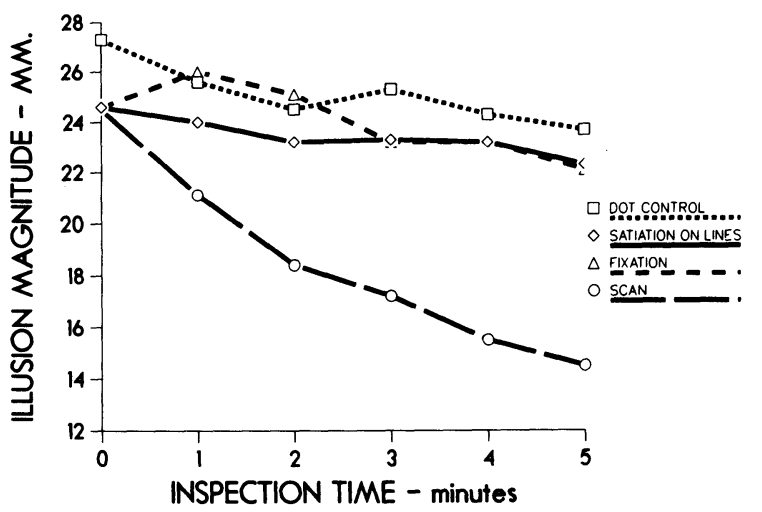

Figure 2. Illusion magnitude plotted against time for each of the four experimental conditions. magnitude only for the group in which there was active scanning of the illusion figure $[F(5,95)=9.87$, $p<.001]$. For each of the other three groups, the change in illusion magnitude over time was not significant. This difference in the pattern of decrement among the groups is further verified by the existence of a significant interaction between inspection condition and viewing time in the overall analysis of variance $[F(15,380)=1.87$, $p<.025$ ]. The source of this interaction is clearly due to the fact that the group that actively scanned the illusion during the inspection periods showed illusion decrement, whereas none of the other groups did.

\section{DISCUSSION}

The results obtained here seem to show that illusion decrement is the result of active saccadic exploration of the illusion figure rather than the result of adaptation or fatigue of the cortical receptors that are stimulated by continued inspection of the illusion configuration. If satiation or fatigue of orientation-specific cortical units were responsible for illusion decrement, the field of parallel lines, slanted to the same orientation as the wings of the illusion figure, should have fatigued the same population of cortical neurons that inspection of the wings would have. This means that we should have obtained significant illusion decrement from the condition in which subjects scanned the field of lines. It might even be argued that an even greater degree of illusion decrement might have been expected, since a grid of $45^{\circ}$ lines would seem to provide a more powerful stimulus for exciting the appropriately tuned orientationspecific cortical cells, than would an array which contained only two such widely spaced line segments. In actuality, the converse is obtained, since little if any decrease in illusion magnitude was observed from inspecting the field of lines, and there was no difference between this condition and the condition in which subjects inspected an array of randomly spaced dots, which would not be expected to produce any predictable pattern of cortical fatigue.

In contrast to predictions from a notion based upon adaptation of a specific population of orientationally responsive cortical cells, the largest amount of illusion decrement was obtained in the condition in which observers actively scanned the illusion configuration itself. The one advantage which this eye movement group has over the others is the opportunity to actively explore the illusion figure itself. In so doing, it seems likely that information about the existence, direction, and extent of an illusory distortion is obtained in the form of error feedback from the overshooting of the ends of the horizontal test extent, which occurs during scanning. In some fashion, this error information seems to be useful in recalibrating the percept toward veridicality. Certainly, simple adaptation of a population of cortical neurons, tuned to the inclination of the wings of the illusion figure, does not seem to be sufficient to bring about a reduction in the magnitude of the illusion which occurs with prolonged viewing of the configuration.

\section{REFERENCES}

Auerbach, F. (1894). Erklaerung der Brentano'schen optischen Tauschung. Zeitschrift für Psychologie, 7, 152-160.

Blakemore, C., Carpenter, R. H. S., \& Georgeson, M. A. (1970). Lateral inhibition between orientation detectors in the human visual system. Nature (London), 228, 37-39.

Burns, B. D., \& PrITChARD, R. (1971). Geometrical illusions and the responses of neurones in the cat's visual cortex to angle patterns. Journal of Physiology, 213, 599-616.

ColthearT, M. (1971). Visual feature-analyzers and aftereffects of tilt and curvature. Psychological Review, 78, 114-121.

Coren, S. (1981). The interaction between eye movements and illusions In D. F. Fisher, R. A. Monty, \& J. W. Senders (Eds.), Eye movements: Cognition and human perception. Hillsdale, $\mathrm{NJ}$ : Erlbaum. 
Coren, S., \& Girgus, J. S. (1972a). Differentiation and decrement in the Mueller-Lyer illusion. Perception \& Psychophysics, 12, 466-470.

Coren, S., \& Girgus, J. S. (1972b). Illusion decrement in intersecting line figures. Psychonomic Science, 26, 108-110.

Coren, S., \& Girgus, J. S. (1974). Transfer of illusion decrement as a function of perceived similarity. Journal of Experimental Psychology, 102, 881-887.

COREn, S., \& GIRGUS, J. S. (1978a). Seeing is deceiving: The psychology of visual illusions. Hillsdale, NJ: Erlbaum.

Coren, S., \& Girgus, J. S. (1978b). Visual illusions. In R. Held, H. Leibowitz, \& H-L Teuber (Eds.), Handbook of sensory physiology. Vol. VIII: Perception (pp. 549-568). Berlin: Springer-Verlag.

Coren, S., Girgus, J. S., Ehrlichman, H., \& Hakstian, A. R. (1976). An empirical taxonomy of visual illusions. Perception \& Psychophysics, 20, 129-137.

Coren, S., \& Hoenig, P. (1972). Eye movements and decrement in the Oppel-Kundt illusion. Perception \& Psychophysics, 12, 224-225.

DAY, R. H. (1962). The effects of repeated trials and prolonged fixation on error in the Mueller-Lyer figure. Psychological Monographs, 76(Whole No. 533).

Festinger, L., White, C. W., \& Allyn, M. R. (1968). Eye movements and decrement in the Mueller-Lyer illusion. Perception \& Psychophysics, 3, 376-382.

GiBson, J. J., \& RADNER, M. (1937). Adaptation, after-effect and contrast in the perception of tilted lines: I. Quantitative studies. Journal of Experimental Psychology, 20, 453-467.

GIRGUS, J. S., \& COREN, S. (1982). Assimilation and contrast illusions: Differences in plasticity. Perception \& Psychophysics, 32, 555-561.

GraHAM, N., \& NaChMias, J. (1971). Detection of grating patterns containing two spatial frequencies: A comparison of single channel and multiple channel models. Vision Research, 11, 251-259.

HARRIS, C. S. (1981). Visual coding and adaptability. Hillsdale, NJ: Erlbaum.
Howard, I. P. (1982). Human visual orientation. New York: Wiley. Koehler, W., \& FishbacK, J. (1950a). The destruction of the MuellerLyer illusion in repeated trials: I. An examination of two theories. Journal of Experimental Psychology, 40, 267-281.

Koehler, W., \& Fishback, J. (1950b). The destruction of the MuellerLyer illusion in repeated trials: II. Satiation patterns and memory trace. Journal of Experimental Psychology, 40, 338-410.

Koehler, W., \& Wallach, H. (1944). Figural after-effects: An investigation of visual processes. Proceedings of the American Philosophical Society, 88, 269-357.

MANSFIELD, R. J. W. (1974). Neural basis of orientation perception in primate vision. Science, 186, 1133-1134.

MitChELL, D. E. (1980). The influence of early visual experience on visual perception. In C. S. Harris (Ed.), Visual coding and adaptability. Hillsdale, NJ: Erlbaum.

Nakagawa, D. (1958). Mueller-Lyer illusion and retinal induction. Psychologia, 1, 167-174.

Parker, N. I., \& Newbigging, P. L. (1963). Magnitude and decrement of the Mueller-Lyer illusion as a function of pre-training. Canadian Journal of Psychology, 17, 134-140.

Porac, C. \& CoRen, S. (1977). The assessment of motor control in sighting dominance using an illusion decrement procedure. Perception \& Psychophysics, 21, 341-346.

Restle, F., \& DeCKer, J. (1977). Size of the Mueller-Lyer illusion as a function of its dimensions: Theory and data. Perception \& Psychophysics, 21, 489-503.

SANFORD, E. C. (1898). A course in experimental psychology: Part I. Sensation and perception. Boston: Heath.

(Manuscript received for publication February 28, 1986.) 